\title{
Evaluation of Protein-DNA Binding Affinity by Electrospray Ionization Mass Spectrometry
}

\author{
Satoko Akashi, Ryo Osawa, and Yoshifumi Nishimura \\ Graduate School of Integrated Science, Yokohama City University, Yokohama, Japan
}

Binding affinity of complexes between a DNA-binding domain (DBD) of a transcription factor, c-Myb, and several double-stranded DNA (dsDNA) were evaluated by collision-induced dissociation (CID) of the multiply protonated molecules generated by electrospray ionization mass spectrometry (ESI-MS). Complexes of the c-Myb DBD and dsDNA were prepared in solution and analyzed by ESI-MS. Multiply protonated molecules of a high-affinity complex, the c-Myb DBD and dsDNA with a specific sequence, were clearly observed in ESI mass spectrum. Protonated molecules of the complex were quite stable in the gas-phase, and not easily dissociated even if high cone voltage was applied in the first vacuum chamber source when the sample was prepared in $10 \mathrm{mM}$ ammonium acetate. As for the sample prepared in buffer with higher concentration of ammonium acetate, such as $500 \mathrm{mM}$ ammonium acetate, protein-dsDNA complexes could easily be dissociated with an increase in the cone voltage, giving multiply protonated molecules of free c-Myb DBD and some DNA fragments. Systematic CID experiments were carried out on seven complexes between the c-Myb DBD and 22-mer dsDNA with different solution-Kd values in the range of $10^{-9} \mathrm{M}$ to $10^{-7} \mathrm{M}$. For each complex dissociation curve as a function of cone voltage was plotted, and the cone voltage where $50 \%$ of the complex was dissociated $\left(\mathrm{V}_{50 \%}\right)$ was calculated. Consequently, positive correlation was obtained between $V_{50 \%}$ and relative binding free energy change $(\Delta \Delta G)$ in complex formation in solution. This suggests that ESI-CID experiments can provide quantitative evaluation of the stability of protein-DNA complexes based on proper calibration. (J Am Soc Mass Spectrom 2005, 16, 116-125) (c) 2004 American Society for Mass Spectrometry

$\mathrm{D}$ evelopment of electrospray ionization (ESI) enabled accurate determination of molecular masses of intact proteins [1]. In addition, ESI-MS has allowed successful detection of noncovalent complexes of biomolecules [2-6]. Direct observation of molecular ions of noncovalent complexes is significant in understanding protein function, because it suggests a target, specificity, and stoichiometry of the specific binding. Maintaining noncovalent complexes during the ESI process sometimes encounters difficulties; no organic solvent should be used for sample preparation, nonvolatile salts should be removed, high temperature during the desolvation process should be avoided, and lower voltages to trigger ESI are preferable. In addition, nonspecific binding in the ion source, sometimes generated by high concentration of the analyte, should be discriminated in the interpretation of mass spectra.

Analyses based on ESI-MS have been employed to measure the solution-phase binding affinity of several protein-ligands or multimeric protein complexes. Rostom et al. indicated that analysis of the proportions of the ion intensity of peptide-bound and free proteins under low-

Published online November 18, 2004

Address reprint requests to Dr. S. Akashi, Graduate School of Integrated Science, Yokohama City University, 1-7-29 Suehiro-cho, Tsurumi-ku, Yokohama, Kanagawa 230-0045, Japan. E-mail: akashi@tsurumi.yokohamacu.ac.jp energy collision conditions by ESIMS gave a good correlation to solution-phase $\mathrm{Kd}$ measurements where available. Increasing the internal energy of the gas-phase complex facilitated to dissociate the complex [7]. We applied this methodology to examine the binding affinity of a protein and double-stranded DNA (dsDNA) complex, a minimal DNA-binding domain (DBD) of a transcription factor c-Myb and oligomeric dsDNA.

$\mathrm{c}-\mathrm{Myb}$ is a transcriptional regulator involved in proliferation and differentiation in haematopoietic lineages [8]. The full DNA-binding domain of c-Myb, which specifically binds to dsDNA with a consensus sequence of AACNG ( $\mathrm{N}$ denotes $\mathrm{A}, \mathrm{T}, \mathrm{C}$, or $\mathrm{G}$ ) [9-11], consists of three homologous tandem repeats of 52 amino acid residues, designated as R1, R2, and R3. Two tandem repeats, R2 and R3, are essential and sufficient for the sequence specific-binding of c-Myb but the first repeat, R1, is not necessary for the sequence specific recognition [12], so the minimal DNA-binding domain (DBD) is an R2R3 fragment. The recognition of dsDNA sequence by c-Myb has been studied extensively by NMR, filter-binding assay, mutation analyses, and other biological assays [10, 11]. The dissociation constant $K d$ values of protein-DNA complexes of the minimal and full DNA-binding domain of c-Myb, R1R2, and R1R2R3, with several 16- and 22-mer dsDNA oligomers, have been determined by filter-binding as- 
say using ${ }^{32} \mathrm{P}$-labeled dsDNA. The binding between R1R2R3 and its specific 22-mer dsDNA (MBS-I 22-mer, $\mathrm{m} 22)$ is very tight with the $\mathrm{Kd}$ of $4.0 \times 10^{-10} \mathrm{M}$ and the $\mathrm{Kd}$ of c-Myb DBD, R2R3, and $\mathrm{m} 22$ is $2.8 \times 10^{-9} \mathrm{M}$ [11]. The size of target DNA is also important for binding of c-Myb. The c-Myb R1R2R3 bound to the 22-mer, 19mer, and 16-mer dsDNA fragments in a sequence specific manner with similar affinities, but for the 13-mer and 10-mer fragments, binding affinity was greatly reduced from $10^{-9} \mathrm{M}$ to $10^{-7} \mathrm{M}$ order, even though it contains specific sequence of AACNG [10].

In order to determine $\mathrm{Kd}$ of a protein-DNA complex, filter-binding assay is a good method but it requires ${ }^{32}$ P-labeled DNA oligomers and a large amount of the protein. Calorimetry can also provide the solution-Kd of a complex but quite a large sample amount is needed. Surface plasmon resonance is another good tool to measure the $\mathrm{Kd}$ of protein-DNA complexes, but it takes several hours to get $K d$ value for each protein-DNA complex. If binding affinity, such as $K d$ values, can be determined by ESI-MS, which does not require special reagents and facilities but can give information also on binding stoichiometry, it should be effective for convenient and high-throughput characterization of proteinDNA interaction.

Compared with protein-ligand or multimeric protein complexes, fewer studies were reported on protein-DNA noncovalent complexes by ESI-MS [1318], although protein-DNA interactions play essential roles in a variety of significant biological processes, such as gene-expression regulation, DNA repair and replication, and transcription regulation, etc. In the protein-DNA interactions, electrostatic forces and hydrogen bonds significantly contribute to the binding of the complex in addition to hydrophobic interactions. As discussed by Daniel et al., interaction energies based on charges, dipoles, and polarizability are expected to increase when going from solution to the gas phase, but hydrophobic interaction is substantially weaker in the absence of solvent [6]. Therefore, in case of a protein-DNA noncovalent complex, it might be possible to detect a weakly bound complex with the $\mathrm{Kd}$ of $10^{-6} \mathrm{M}$ if the sample can be prepared at this concentration.

We applied ESI-MS for the evaluation of the binding affinity between the c-Myb DBD and dsDNA. In normal ESI-MS analyses, sample solution is prepared in low- $\mu \mathrm{M}\left(10^{-6} \mathrm{M}\right)$ concentration that is sufficient enough for the detection of multiply protonated molecules. Therefore, it is not so easy to differentiate the interaction levels from $10^{-7} \mathrm{M}$ to $10^{-9} \mathrm{M}$ order with normal ESI-MS analyses. To overcome this problem, we optimized sample preparation for ESI-MS measurement for a systematic estimation of binding affinity over two orders of magnitude. We present here a convenient method to characterize the proteinDNA binding affinity using CID in the first vacuum chamber source.

\section{Materials and Methods}

All reagents used were analytical grade. Water was purchased from Merck (Darmstadt, Germany), and ammonium acetate (ReagentPlus, 99.99+\%) was from Aldrich (Milwaukee, WI). The c-Myb DBD with the sequence of MELIKGPWTKEEDQRVIKLQKYGPKRWSVIAKHLKGRIGKQCRERWHNHLNPEVKKTSWTEEEDRIIYQAHKRLGNRWAEIAKLLPGRTDNAIKNHWNSTMRRKV was prepared as previously described $[19,20]$. Briefly, the c-Myb DBD was expressed in E. coli BL21(DE3) using a T7 expression system, grown in SB medium, and purified by successive column chromatography using phosphocellulose (P11, Whatman, Brentford, UK), carboxymethyl-cellulose (CM52, Whatman, Brentford, UK), phenyl-sepharose (Amersham, Piscataway, NJ), and Superdex 75 (Amersham, Piscataway, NJ) columns. The stock solution of the c-Myb DBD was prepared in $100 \mathrm{mM}$ potassium phosphate $(\mathrm{pH}$ 6.7) with $10 \mathrm{mM}$ dithiothreitol and $1 \mathrm{mM}$ sodium azide by ultrafiltration using Ultrafree (MW cut off 10,000, Millipore, Billerica, MA) and stored at $4{ }^{\circ} \mathrm{C}$ before use. The concentration of the c-Myb DBD in stock solution was estimated from UV absorbance at $280 \mathrm{~nm}$ using the $\varepsilon_{280}$ $=36.2 \times 10^{3} \mathrm{M}^{-1} \mathrm{~cm}^{-1}$ for c-Myb DBD. Chemically synthesized 16- and 22-mer single-stranded DNA (ssDNA) oligomers were purchased from Bex Co. Ltd. (Tokyo, Japan). Each ssDNA was dissolved in $1 \mathrm{M}$ ammonium acetate buffer ( $\mathrm{pH}$ 6.7) and its concentration was estimated from UV absorbance at $260 \mathrm{~nm}$. Two complementary ssDNA were annealed by cooling slowly from $95^{\circ} \mathrm{C}$ to room temperature in $1 \mathrm{M}$ ammonium acetate buffer ( $\mathrm{pH} 6.7$ ), resulting in $0.5 \mathrm{mM}$ dsDNA stock solution. Annealed dsDNA stock solution was stored at $4{ }^{\circ} \mathrm{C}$ before use.

\section{Preparation of DNA-Protein complex}

A $3 \mu \mathrm{L}$ aliquot of c-Myb DBD stock solution (1.6 mM) was diluted with $340 \mu \mathrm{L}$ of $10 \mathrm{mM}$ ammonium acetate ( $\mathrm{pH}$ 6.7), and then $10 \mu \mathrm{L}$ of dsDNA stock solution (0.5 mM) was added and mixed. The sample solution was ultrafiltrated against $10 \mathrm{mM}$ ammonium acetate ( $\mathrm{pH}$ 6.7) using Millipore Ultrafree (MW cut off 5000) and $100 \mu \mathrm{M}$ solution of protein-DNA complex was prepared.

Binding activity of the c-Myb DBD to some dsDNA oligomers was also confirmed by gel-mobility assay. A $20 \mu \mathrm{L}$ aliquot of $5 \mu \mathrm{M}$ dsDNA oligomers with or without c-Myb DBD was applied on a 15\% acrylamidegel, and electrophoresis was carried out with $1 \times \mathrm{TBE}$ buffer ( $90 \mathrm{mM}$ Trizma base, $90 \mathrm{mM}$ boric acid, $2 \mathrm{mM}$ EDTA). After the electrophoresis the gel was stained with ethidium bromide.

\section{Mass Spectrometry}

Prior to ESI-MS analyses, extensive buffer exchange was carried out using Millipore Ultrafree, and $100 \mu \mathrm{M}$ 
c-Myb DBD or $100 \mu \mathrm{M}$ c-Myb DBD-dsDNA complex in $10 \mathrm{mM}$ ammonium acetate solution $(\mathrm{pH} 6.7)$ was prepared, as described above. This solution was diluted with appropriate concentration of ammonium acetate buffer $(10 \sim 880 \mathrm{mM})$ to make the analyte concentration $10 \mu \mathrm{M}$, and then subjected to ESIMS analyses. Electrospray ionization mass spectra were obtained by Q-TOF2 (Waters, Milford, MA) with an electrospray ion source. Spectra were calibrated with $(\mathrm{NaI})_{n} \mathrm{Na}^{+}$. MassLynx version 3.4 software (Waters, Milford, MA) was used for data processing and peak integration.

The ion source and desolvation gas temperature was set to $80^{\circ} \mathrm{C}$ and $120^{\circ} \mathrm{C}$, respectively. The sample was introduced into the ESI source at a flow rate of $5 \mu \mathrm{L} / \mathrm{min}$ with a syringe pump. To observe the dissociation of protonated molecule of a protein-DNA complex, cone voltage of the ESI ion source was increased by $5 \mathrm{~V}$ stepwise. Mass spectra were obtained at various cone voltages, from 50 to $100 \mathrm{~V}$ for each complex. Experiments were repeated three times. The percentage of complex was obtained by calculating the ratio of the ion intensity of the complex to the total ion intensity. The change of the percentage of complex was plotted as a function of cone voltage and dissociation curve was obtained for each c-Myb DBD-dsDNA complex. The correlation between cone voltage of the $50 \%$ complex content $\left(\mathrm{V}_{50 \%}\right)$ and solution-phase $\Delta \Delta G(\mathrm{kcal} / \mathrm{mol})$, which was determined by filter-binding assay, [11] was investigated for each protein-dsDNA complex.

\section{Results and Discussion}

\section{Observation of c-Myb DBD-dsDNA (16-mer) Complex}

The DNA binding affinity of the c-Myb DBD to its specific dsDNA, MBS-I 16-mer (MBS-I 16, 5' CCTAACTGACACACAT $3^{\prime}(+)$ and its complementary strand $(-)$, was confirmed by gel-mobility assay. The dissociation constant in solution $(100 \mathrm{mM}$ potassium phosphate buffer ( $\mathrm{pH} 7.5$ ) with $20 \mathrm{mM} \mathrm{KCl}, 0.1 \mathrm{mM}$ EDTA, $500 \mu \mathrm{g} / \mathrm{mL}$ of bovine serum albumin, $5 \%$ (vol/ vol) glycerol and $10 \mathrm{mM}$ dithiothreitol) of this complex had been determined as $\mathrm{Kd}=3.8 \times 10^{-9} \mathrm{M}$ by filter-binding assay [10]. Figure 1a shows an image of gel-mobility assay of MBS-I 16 in the presence and absence of the c-Myb DBD. In the presence of the c-Myb DBD, complete band-shift of MBS-I 16 was observed, indicating that MBS-I 16 was specifically recognized by the c-Myb DBD. Figure 1b shows ESI mass spectra of $10 \mu \mathrm{M}$ of the c-Myb DBD (lower panel) and c-Myb DBD-dsDNA complex (upper panel) in $10 \mathrm{mM}$ ammonium acetate buffer ( $\mathrm{pH}$ 6.7). The most intense peak for the protein-dsDNA complex was $[\mathrm{M}+10 \mathrm{H}]^{10+}$ while that for the free protein was $[\mathrm{M}+8 \mathrm{H}]^{8+}$. In ESI mass spectrum of the protein-DNA complex (Figure $1 \mathrm{~b}$ upper panel), only protonated molecule of the c-Myb DBDdsDNA complex was observed, and no ions of free c-Myb DBD and dsDNA were observed. This indicates (a)

(b)

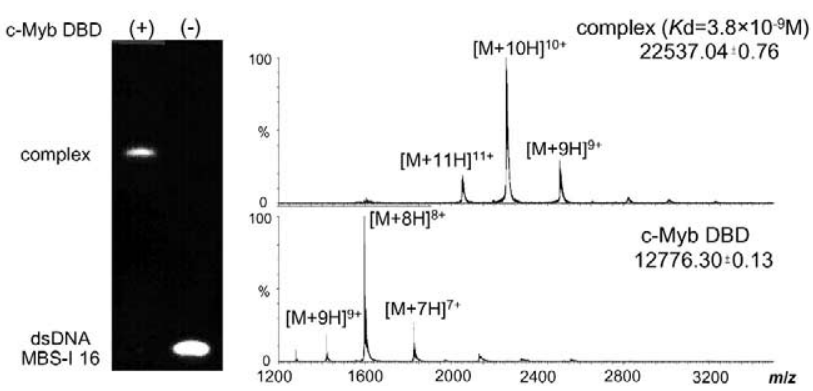

Figure 1. Examination results of binding affinity of c-Myb DBD and dsDNA oligomer, MBS-I 16. (a) An image of gel-mobility assay of MBS-I 16 (5' CCTAACTGACACACAT 3' \{MW 4793.2\} and its complementary strand (MW 4968.3\}) in the presence (left) and absence (right) of c-Myb DBD. (b) ESI mass spectra of free c-Myb DBD (lower panel) and a complex of c-Myb DBD and MBS-I 16 (upper panel).

that interaction between the c-Myb DBD and the dsDNA, MBS-I 16, is stable enough to maintain the complex during the electrospray ionization process.

\section{Effect of Cone Voltage and Salt Concentration on Complex Dissociation}

In order to investigate dissociation process of the complex in the gas-phase, collision-induced dissociation (CID) experiments were carried out. One of the multiply protonated molecules of the protein-dsDNA complex, $[\mathrm{M}+10 \mathrm{H}]^{10+}$, was isolated and subjected to CID in the collision cell by increasing the collision energy, but no ion of the dissociated protein was observed in the product ion spectrum (data not shown). Then CID in the first vacuum chamber source was examined for the protein-dsDNA complex by increasing the cone voltage, because it was expected that collision efficiency would be increased if CID process is carried out under low vacuum region. Figure 2 shows the effect of cone voltage increase on ESI mass spectra of the complex of c-Myb DBD with MBS-I 16 (Figure 2a) and free c-Myb DBD (Figure $2 \mathrm{~b}$ ) prepared in $10 \mathrm{mM}$ ammonium acetate. As shown in Figure 2a, high cone voltage up to $100 \mathrm{~V}$ did not allow us to observe the protonated molecules of the dissociated free c-Myb DBD while protonated molecule of the complex showed extreme peak-broadening. In contrast, no remarkable change was recognized in the mass spectra of free c-Myb DBD when increasing the cone voltage (Figure $2 \mathrm{~b}$ ). This suggests that free c-Myb DBD can be ionized and stable enough at a wide range of cone voltage. In mass spectra of the complex (Figure 2a), low abundant ions at mass values corresponding to complexes with a mass 100 $150 \mathrm{Da}$ lower than ions from the intact complex appeared at cone voltages higher than $70 \mathrm{~V}$. These ions are interpreted as the product of depurination of DNA [16] caused by high cone voltage. It has also been reported that such degradation of DNA in protein-DNA complexes in CID experiment was observed for Trp repres- 


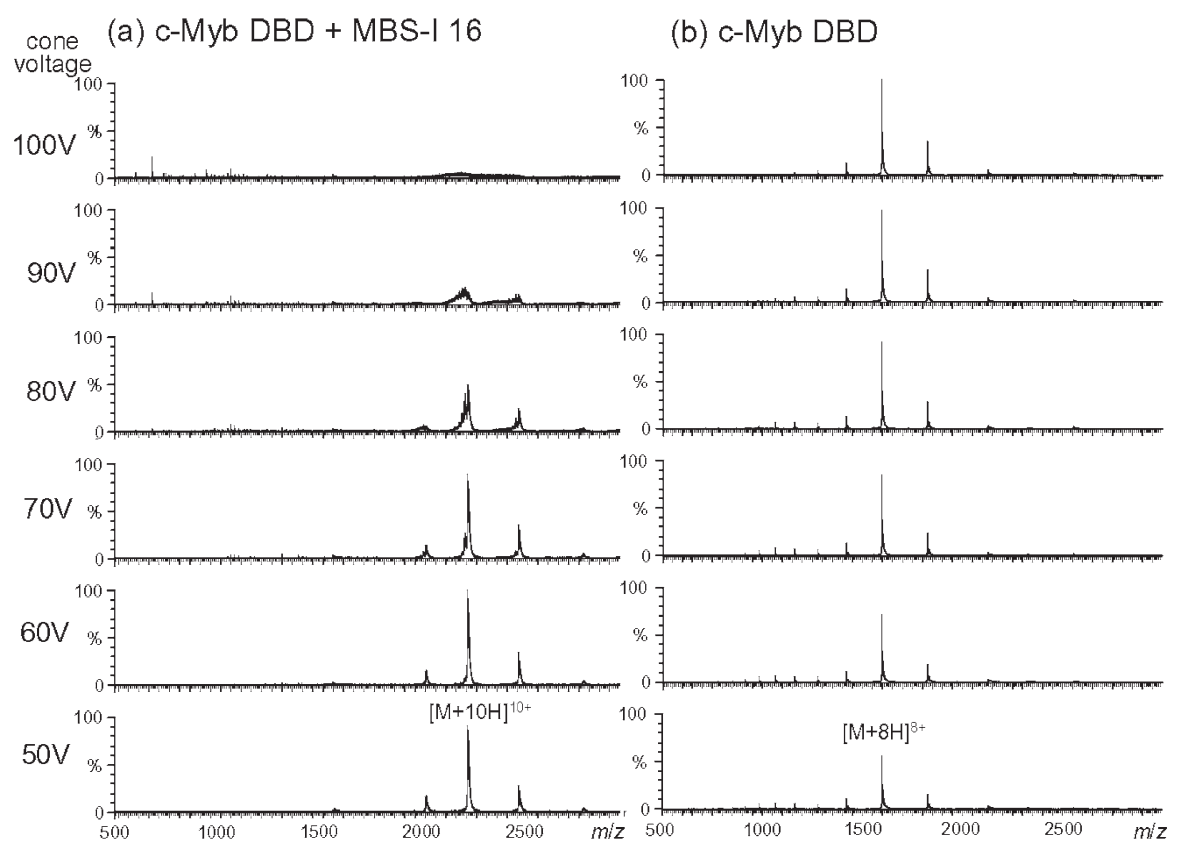

Figure 2. ESI mass spectra of (a) a complex of c-Myb DBD with MBS-I 16 and (b) c-Myb DBD in $10 \mathrm{mM}$ ammonium acetate obtained at cone voltages of 50,60,70, 80, 90, and $100 \mathrm{~V}$. Mass spectra at various cone voltages are normalized to the most intense peak in each dataset (a) or (b), respectively.

sor and replication terminator protein Tus [14]. In addition, some singly charged ions were also observed in the low $m / z$ region $(500-1300)$ in mass spectra of the complex when the cone voltage increased to $80-100 \mathrm{~V}$. These singly charged ions were assigned to DNA fragments.

Since protein-DNA interaction involves many electrostatic contacts, it was expected that high salt concentration would weaken the interaction and destabilize the complex, as discussed in a previous paper [14]. Thus, effect of salt concentration was examined on the complex of c-Myb DBD and MBS-I 16. By increasing ammonium acetate concentration up to $150 \mathrm{mM}$, not only multiply protonated molecules of the c-Myb DBDdsDNA complex but also those of free c-Myb DBD and ssDNA were observed at $50 \mathrm{~V}$ of cone voltage, as shown in Figure 3a. As the concentration of ammonium acetate elevated, relative intensity of the dissociated c-Myb DBD, ssDNA, and dsDNA increased while that of the protein-dsDNA complex decreased. In the absence of dsDNA, no significant changes in ESI mass spectra of c-Myb DBD were observed according to the increase in the concentration of ammonium acetate, as shown in Figure $3 \mathrm{~b}$. In order to investigate the dissociation of protein-dsDNA complexes with wide range of $\mathrm{Kd}$, extensive investigation on the concentration of ammonium acetate was carried out for two protein-DNA complexes of c-Myb DBD with 22-mer dsDNA, m22 (5' CACCCTAACTGACACACATTCT $3^{\prime}$ \{MW 6583.4\} and its complementary strand $\{\mathrm{MW} 6885.5\})$ and $\mathrm{m} 14\left(5^{\prime}\right.$ CACCCTAACTCACACACATTCT 3' \{MW 6543.3\} and its complementary strand (MW 6925.6\}). Oligonucleotide $\mathrm{m} 22$ has wild-type sequence that the c-Myb DBD can specifically recognize. Oligonucleotide $\mathrm{m} 14$ is a single-substitution mutant of $\mathrm{m} 22$. The solution-Kd for these two complexes had been determined by filter binding assay as $2.8 \times 10^{-9} \mathrm{M}$ and $6.3 \times 10^{-7} \mathrm{M}$, respectively [11]. Figure 4 shows ESI mass spectra of the complex of c-Myb DBD with m22 prepared in 10, 200, and $500 \mathrm{mM}$ ammonium acetate. Spectra at cone voltages of 50,60, 70, 80, and $90 \mathrm{~V}$ were indicated. For the complex prepared in $10 \mathrm{mM}$ ammonium acetate, only peak-broadening was observed when increasing the cone voltage up to $90 \mathrm{~V}$ (Figure 4a). The complex prepared in $200 \mathrm{mM}$ ammonium acetate gave quite a low-intense peak of $[\mathrm{M}+8 \mathrm{H}]^{8+}$ of the $\mathrm{c}-\mathrm{Myb} \mathrm{DBD}$ at any cone voltage, that is, dissociation of the complex was not facilitated by the increase of the cone voltage. Considerable peak-broadening was observed for multiply protonated molecules of the complex at high cone voltage $(>70 \mathrm{~V})$ (Figure $4 \mathrm{~b}$ ). In case of the complex prepared in $500 \mathrm{mM}$ ammonium acetate, intensity of the dissociated protein peak improved when the cone voltage rose (Figure 4c). Consequently, concentration of ammonium acetate was optimized around $500 \mathrm{mM}$ using the two protein-DNA complexes, with $\mathrm{Kd}$ differing by two orders of magnitudes in solution. Figure 5 summarizes the effect of the cone voltage on the complexes prepared in 400,500, and $600 \mathrm{mM}$ ammonium acetate. The percentage of complex, which was calculated from the peak height of the most intense peak among the observed charge states, was plotted as a function of the cone voltage for each condition. Figure $5 b$ and $c$ suggest that the high-affinity complex, c-Myb DBD with m22, in 500 or $600 \mathrm{mM}$ ammonium acetate could completely be dissociated at $100 \mathrm{~V}$. When the 


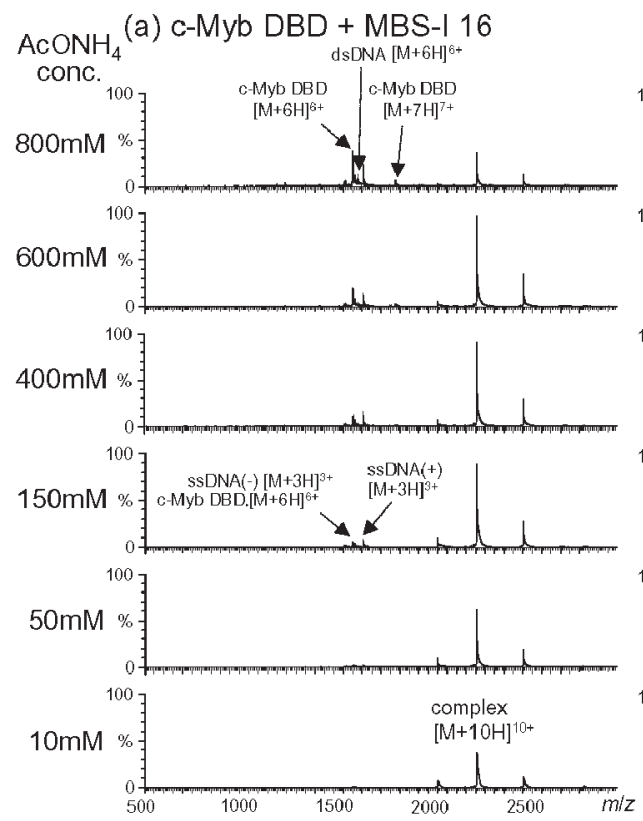

(b) c-Myb DBD

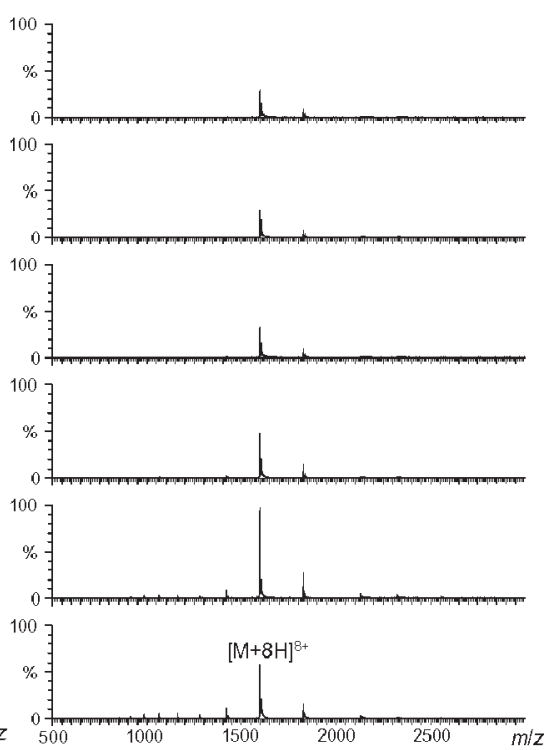

Figure 3. ESI mass spectra of (a) a complex of c-Myb DBD with MBS-I 16 and (b) c-Myb DBD prepared in buffer with various concentration of ammonium acetate $(10,50,150,400,600$, and $800 \mathrm{mM}$ ) obtained at $50 \mathrm{~V}$ of cone voltage. Mass spectra are normalized to the most intense peak in each dataset $(\mathbf{a})$ or $(\mathbf{b})$, respectively.

sample was prepared in $400 \mathrm{mM}$ ammonium acetate, $36 \%$ of the complex still survived even at $100 \mathrm{~V}$ of the cone voltage. The percentage of complex at $50 \mathrm{~V}$ was $32 \%$ for the low-affinity complex, c-Myb DBD with $\mathrm{m} 14$, prepared in $400 \mathrm{mM}$ ammonium acetate. When the complex of c-Myb DBD with m14 was prepared in $600 \mathrm{mM}$ ammonium acetate, the complex formation was hardly accomplished and the percentage of complex was less than $10 \%$ even at $50 \mathrm{~V}$ of the cone voltage. This indicates that $600 \mathrm{mM}$ ammonium acetate is not relevant to observe the dissociation of weakly bound protein-DNA complexes. To characterize the binding affinity in a wide range, the buffer with $500 \mathrm{mM}$ ammonium acetate was selected for the preparation of

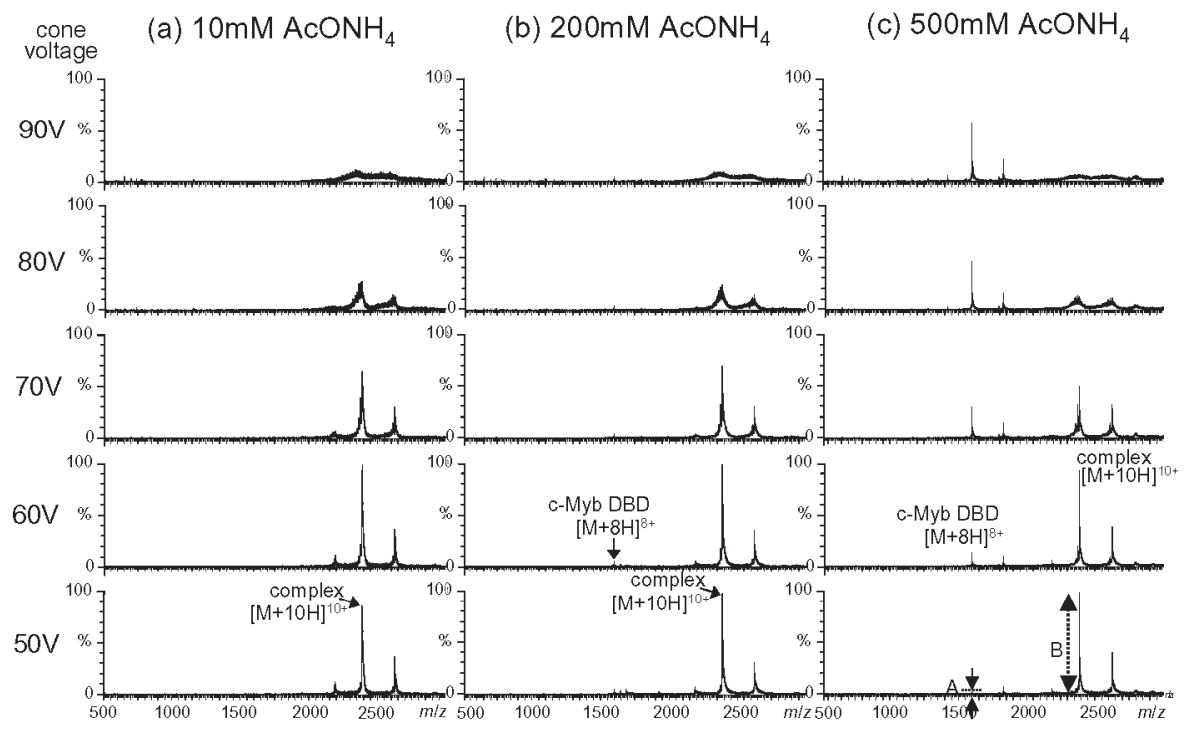

Figure 4. ESI mass spectra of a complex of c-Myb DBD with m22 in (a) $10 \mathrm{mM}$, (b) $200 \mathrm{mM}$, and (c) $500 \mathrm{mM}$ ammonium acetate obtained at 50,60, 70, 80, and $90 \mathrm{~V}$ of cone voltage. Mass spectra at various cone voltages are normalized to the most intense peak in each dataset $(\mathbf{a}),(\mathbf{b})$, or (c), respectively. The percentage of complex $(R)$ was calculated by the equation of $R=\{B /(A+B)\} \times 100$, where $A$ is the peak intensity of $[\mathrm{M}+8 \mathrm{H}]^{8+}$ of the free $\mathrm{c}-\mathrm{Myb} \mathrm{DBD}$ and $\mathrm{B}$ is that of $[\mathrm{M}+10 \mathrm{H}]^{10+}$ of the complex, as indicated in panel (c). The $\mathrm{R}$ value was used for plotting the dissociation curves shown in Figure 5. 
(a) $400 \mathrm{mM} \mathrm{AcONH}_{4}$

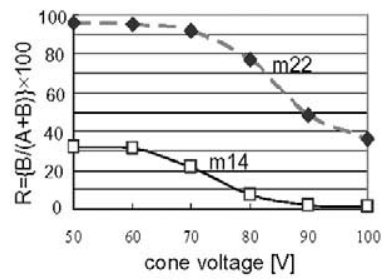

(b) $500 \mathrm{mM} \mathrm{AcONH}_{4}$

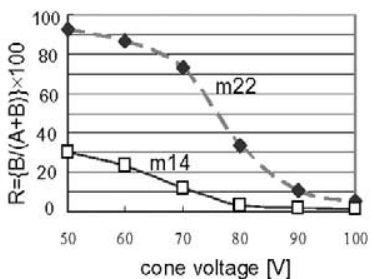

(c) $600 \mathrm{mM} \mathrm{AcONH}_{4}$

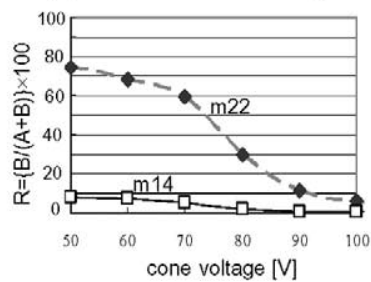

Figure 5. Plots of the percentage of complex as a function of cone voltage for the complexes of c-Myb DBD with m22 (filled diamond) and c-Myb DBD with m14 (open square) in (a) $400 \mathrm{mM}$, (b) $500 \mathrm{mM}$, and (c) $600 \mathrm{mM}$ ammonium acetate. The percentage of complex (R) was calculated as indicated in the legends of Figure 4.

the seven protein-DNA complexes with various solution- $\mathrm{Kd}$. The samples prepared in $500 \mathrm{mM}$ ammonium acetate were then subjected to further ESI-MS experiments.

Peak-broadening, which was observed in the spectra at high cone voltage for all samples prepared in buffer with different concentration ammonium acetate, is considered to be a product of depurination of DNA [16], as discussed above. Samples prepared in lower concentration of ammonium acetate gave few dissociated free protein peaks at any cone voltage (Figure $4 a$ and $b$ ) while multiply protonated ions of free c-Myb DBD were clearly observed at higher cone voltage for the complex prepared in $500 \mathrm{mM}$ ammonium acetate (Figure 4c). This suggests that DNA fragmentation does not allow the release of the protein from the complex prepared in lower concentration of ammonium acetate. Noncovalent bonds between DNA and protein appear to be more stable than covalent bonds between nucleic base and sugar moiety in DNA when the sample was prepared in buffer with low salt concentration. The dsDNA with different sequence or length may result in different fragmentation behavior of DNA in the protein-dsDNA complex, and less peak-broadening or higher free protein peaks might be observed in ESI-CID spectra. High content of G-C pairs may also affect the stability of the dsDNA-protein complex.

\section{Characterization of the Complex Stability by CID}

In order to evaluate the stability of the c-Myb DBDdsDNA complexes with different solution-phase $\mathrm{Kd}$

Table 1. Sequences of MBS-I 16 and seven 22-mer dsDNA with $\Delta \Delta \mathrm{G}[\mathrm{kcal} / \mathrm{mol}]$ and $\mathrm{Kd}[\mathrm{M}]$ of the complex with c-Myb DBD determined by previous filter-binding assay [11]

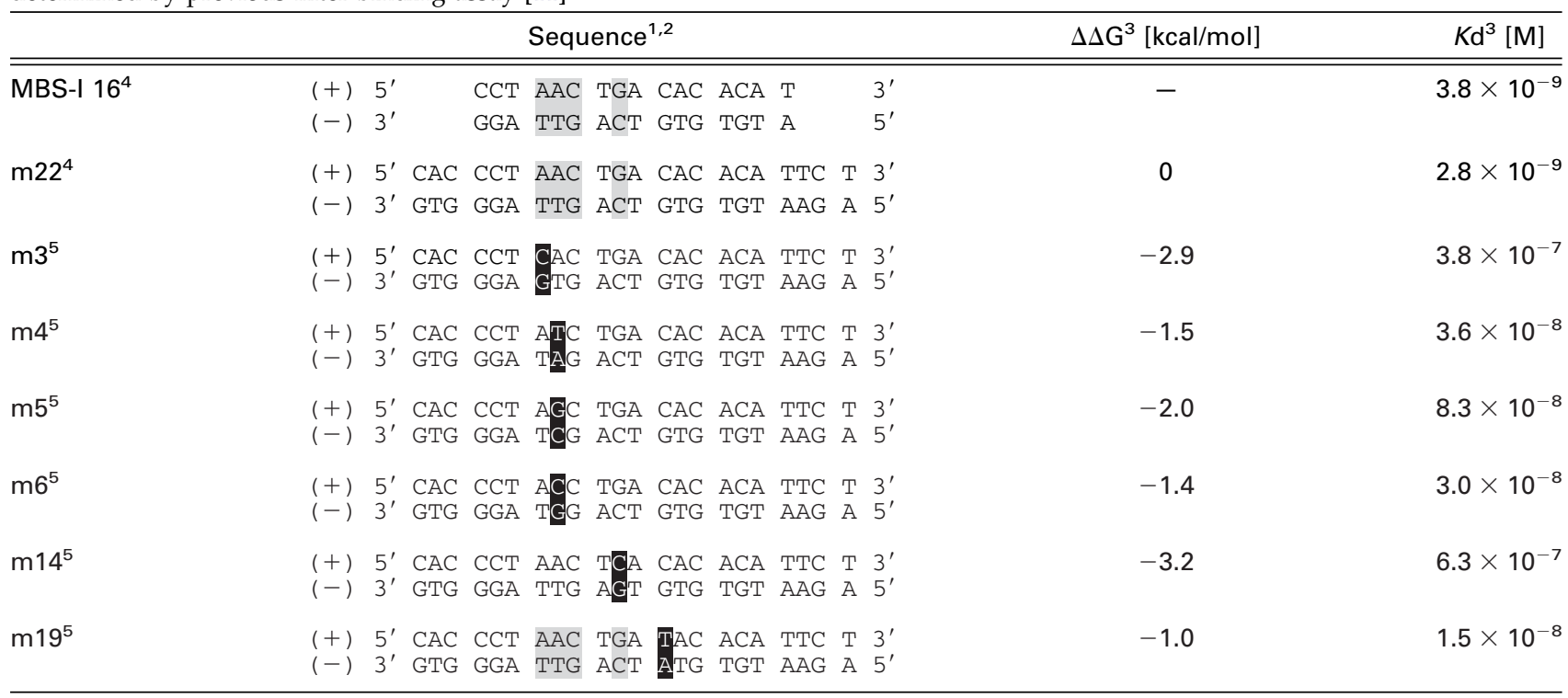

${ }^{1}$ Dashed boxes indicate the consensus sequence which c-Myb DBD specifically recognizes.

${ }^{2} \mathrm{Gray}$ boxes indicate the mutated positions in mutant dsDNA.

${ }^{3}$ Relative binding free energy change associated with the base-pair substitution can be calculated by the following equation: $\Delta \Delta G=\Delta G m-$ $\Delta G w t=-R T \ln \frac{K d(m)}{K d(w t)} \Delta G m: \Delta G$ for mutant, $\Delta G w t: \Delta G$ for wild type (m22) $K d(m): K d$ for mutant, $K d(w t): K d$ for wild type (m22) Kd for each complex was determined by filter-binding assay. The DNA and c-Myb DBD was incubated in buffer (100mM potassium phosphate (pH7.5), 20mM KCl, 0.1 $\mathrm{mM}$ EDTA, $500 \mu \mathrm{g} / \mathrm{mL}$ of BSA, $5 \%$ glycerol (v/v), $10 \mathrm{mM}$ dithiothreitol) on ice, and then filtered through nitrocellulose under suction [11]. ${ }^{4}$ Sequences of MBS-1 16 and $\mathrm{m} 22$ are wild-type.

${ }^{5} \mathrm{~m} 3, \mathrm{~m} 4, \mathrm{~m} 5, \mathrm{~m} 6, \mathrm{~m} 14$, and $\mathrm{m} 19$ are single point mutants of $\mathrm{m} 22$. 
(a) $c-M y b D B D+m 22 \cdot\left(K d=2.8 \times 10^{-9} M\right)$

voltage
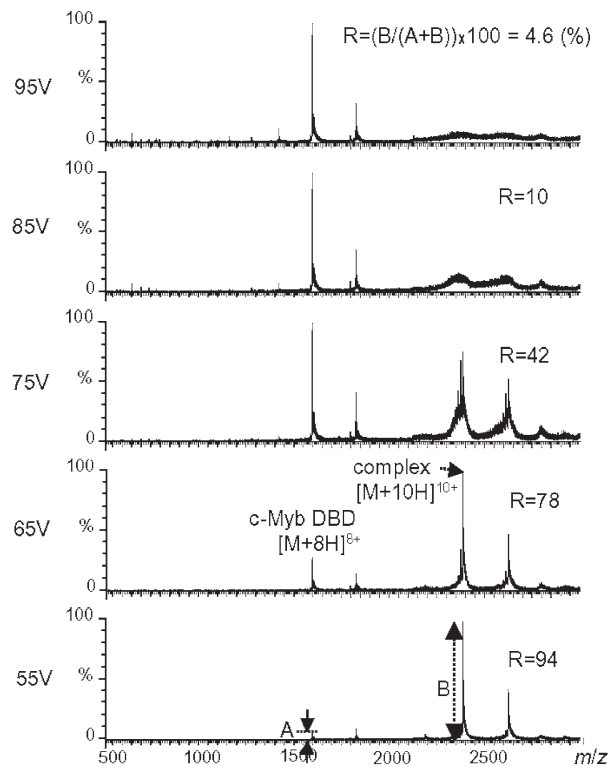

(b) c-Myb DBD + m14 $\left(K \mathrm{~d}=6.3 \times 10^{-7} \mathrm{M}\right)$

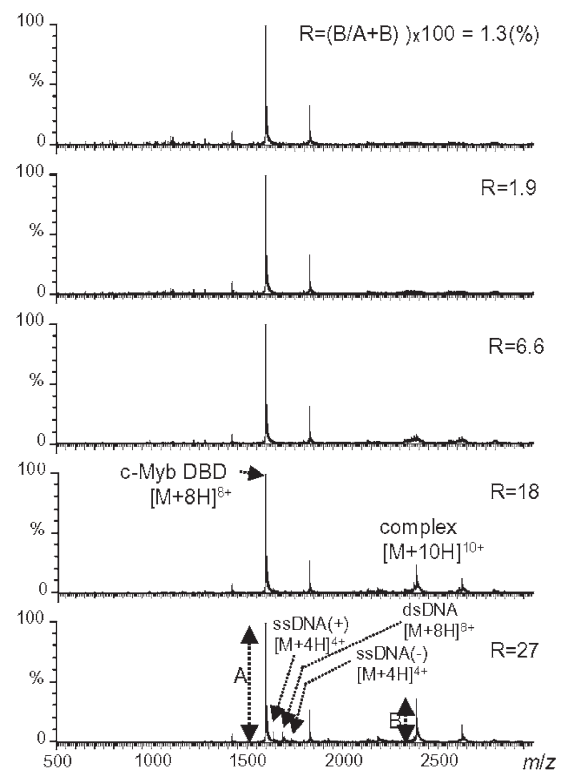

Figure 6. ESI mass spectra of complexes of (a) c-Myb DBD with $\mathrm{m} 22$ and (b) c-Myb DBD with m14 in $500 \mathrm{mM}$ ammonium acetate obtained at 55, 65, 75, 85, and $95 \mathrm{~V}$ of cone voltage. The most intense peak in each mass spectrum is indicated as a base peak. The percentage of complex $(R)$ was calculated by the equation of $\mathrm{R}=\{\mathrm{B} /(\mathrm{A}+\mathrm{B})\} \times 100$, where $\mathrm{A}$ is the peak intensity of $[\mathrm{M}+8 \mathrm{H}]^{8+}$ of the free $\mathrm{c}-\mathrm{Myb} \mathrm{DBD}$ and $\mathrm{B}$ is that of $[\mathrm{M}+10 \mathrm{H}]^{10+}$ of the complex. The $\mathrm{R}$ value at each cone voltage is indicated in each ESI mass spectrum.

values, ESI mass spectra of various complexes prepared in $500 \mathrm{mM}$ ammonium acetate were acquired at different cone voltages and the dissociation curve of each complex as a function of cone voltage was plotted. Table 1 summarizes sequences of the examined dsDNA and solution-phase $\mathrm{Kd}$ of the complexes with $\mathrm{c}-\mathrm{Myb}$ DBD determined by filter-binding assay [11]. Figure 6a indicates ESI mass spectra of the complex of c-Myb DBD with $\mathrm{m} 22$ in $500 \mathrm{mM}$ ammonium acetate solution obtained at various cone voltages. In contrast to ESI mass spectra obtained for the complex in $10 \mathrm{mM}$ ammonium acetate (Figure 4a), not only protonated molecules of the complex but also those of the dissociated protein were clearly observed in each spectrum. As the cone voltage increased, peak intensities of the c-Myb DBD-DNA complex were reduced while those of the free c-Myb DBD improved. Since the released DNA molecule is not as stable as the protein at high cone voltage, many singly charged fragment ions derived from the dissociated DNA molecule were observed in the low mass region $(\mathrm{m} / \mathrm{z}$ 500-1300). Peak-broadening of the complex ions caused by depurination of DNA was also recognized at high cone voltage. In case of the low-affinity complex of c-Myb DBD with m14, as shown in Figure 6b, the base peak in the spectrum was $[\mathrm{M}+8 \mathrm{H}]^{8+}$ of the c-Myb DBD, not multiply protonated molecules of the complex, even at $55 \mathrm{~V}$ of cone voltage. At $55 \mathrm{~V}$, multiply charged molecules of dsDNA and two dissociated ssDNA were also observed in the spectrum. These DNA molecular ions disappeared when the cone voltage rose to $65 \mathrm{~V}$. This should be caused by the following: (1) protonated molecules of DNA are not so stable at higher cone voltage, (2) ionization efficiency of a protein is much higher than that of DNA, and (3) detection sensitivity of DNA is much lower than that of a protein in positive ion mode. At $85 \mathrm{~V}$, protonated molecules of the intact complex almost disappeared and only those of dissociated c-Myb DBD and several fragments of DNA were observed in ESI mass spectrum. By comparing these two datasets, it appears that gas-phase stability has correlation with solution-phase stability of the protein-DNA complex, as previously reported [14]. To examine gas-phase stability of the c-Myb DBDdsDNA complexes quantitatively, the percentage of bound protein was calculated at each cone voltage using peak height of the most intense peak among the observed charge states for the complex and that for the released protein. The average value $(n=3)$ of the percentage of each complex was plotted as a function of cone voltage, as shown in Figure 7.

For more quantitative analysis of binding affinity of protein-DNA complexes, we also examined to use peak-area instead of peak-height for calculation of the percentage of complex. In estimation of peak-area of the protonated molecules of the protein-DNA complex, depurination of DNA and adduct of ammonium was also taken into account. Peak-broadening for the complex signal was significant at high cone voltage, as mentioned above, and only a little reduction in the peak-area was found when the cone voltage rose. In contrast, peaks of protonated molecules of free protein were much narrower than those of the protein-DNA 


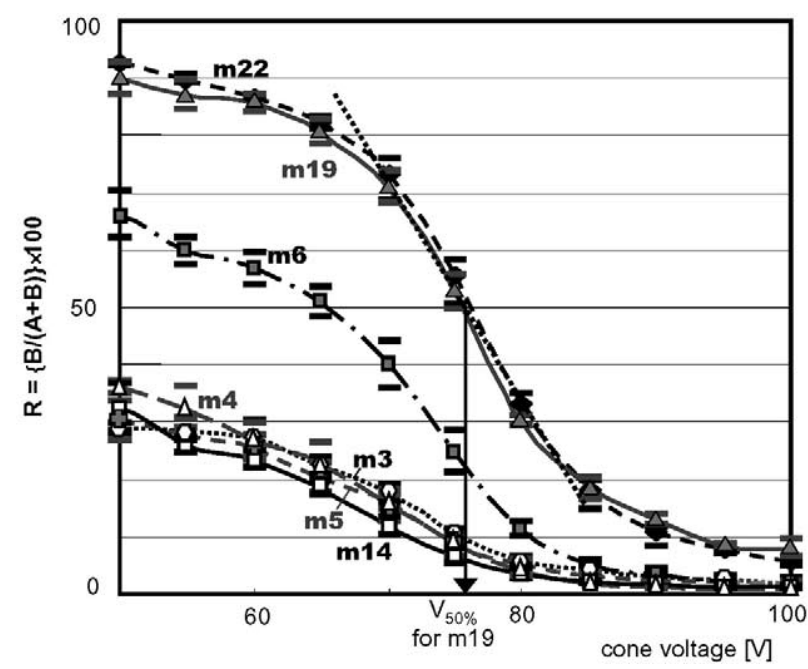

Figure 7. Plots of the percentage of complex as a function of cone voltage for seven c-Myb DBD-dsDNA complexes. Each dissociation curve was plotted by using the average $\mathrm{R}$ values obtained by three independent experiments. The SD for each data point is also indicated. In case of c-Myb DBD complexes with m22, m19, and $\mathrm{m} 6, \mathrm{~V}_{50 \%}$ was determined from the crossing point of linear part of the sigmoid curve on $50 \%$ line of the percentage of complex $(\mathrm{R}=$ 50). In case of c-Myb DBD complexes with $\mathrm{m} 3, \mathrm{~m} 4, \mathrm{~m} 5$, and $\mathrm{m} 14$, linear part of the sigmoid curve was extrapolated toward lower cone voltage and the crossing point on $50 \%$ line $(R=50)$ was operated for $V_{50 \%}$. An example how to determine $V_{50 \%}$ value is indicated for the complex with $\mathrm{m} 19$ with a dotted line and an arrow.

complex. Thus, the effect of the increase in the peakarea of free protein was negligible on the calculation of the percentage of complex while a change of the peakheight was remarkable as the cone voltage increased. As a result, little change was recognized as the cone voltage increase in the percentage of complex by calculation using the peak-area (data not shown). In contrast, the percentage of complex calculated from the peakheight gave more distinct change. We also examined the calculation of the ratio of free and bound form of the c-Myb DBD by summing the intensities of all ions from the free protein and all ions from the complex, but there was no remarkable difference from the results calculated by the peak-height of the most intense peaks (data not shown). This should be caused by the fact that charge distribution of the complex and dissociated protein was not affected by the increase of the cone voltage, as shown in Figure 6. Therefore, we adopted to use the peak height of the most intense peak to analyze the binding affinity of the c-Myb DBD and dsDNA.

Although the dissociation curve could be plotted successfully for each complex as shown in Figure 7, it should be noted that the percentage of complex calculated using the peak-height of the most intense peak may not represent the real population of free and bound protein. In the present study, singly mutated oligonucleotides composed of 22 base pairs were used for the investigation of the binding affinity to the c-Myb DBD. Since a single mutation among 22 base pairs is expected to affect little on ionization and detection efficiency of the protein-DNA complex, signal intensity of each complex would be the same if an equal amount of the complex exists in the sample. Ionization and detection efficiency of the free protein would be much higher than that of the protein-DNA complexes in positive-ion mode. Relative intensity of the complex signals might be reduced by suppression effect of coexisting free protein that cannot be bound to dsDNA. To compensate this difference, Kapur et al. analyzed the relative ESIMS response factors of free and bound protein, Tus, with dsDNA [14]. In their case, the response factors of free and bound protein were found to be almost the same. We carried out similar experiments on the complex of c-Myb DBD and $\mathrm{m} 22$ by changing the mixing ratio of each component (data not shown). It was confirmed that dissociation of the complex can be observed even in the presence of excess free c-Myb DBD. Relative intensity of the complex signal was hardly affected by the presence of excess free protein. Increase of the intensity of protein peaks can be observed in the presence of excess free protein but it appears be better to carry out further compensation for more accurate quantitative analyses. This will be discussed below.

Dissociation curves in Figure 7 suggest that dissociation behaviors of the complexes can be grouped roughly into three types. Two dsDNA, m22 and $\mathrm{m} 19$, showed high binding affinity to the c-Myb DBD. They were little dissociated at $50 \mathrm{~V}$ of cone voltage but almost completely dissociated at $90 \mathrm{~V}$. In contrast, four dsDNA, $\mathrm{m} 3, \mathrm{~m} 4, \mathrm{~m} 5$, and $\mathrm{m} 14$, showed low binding affinity to the c-Myb DBD. The percentage of the complex was less than $40 \%$ at $50 \mathrm{~V}$ of cone voltage and it decreased to less than $10 \%$ when the cone voltage rose to $75 \mathrm{~V}$. The other dsDNA, m6, showed in-between binding affinity to c-Myb DBD.

In order to investigate the relationship between the solution-phase $K \mathrm{~d}$ and gas-phase stability of the complex, cone voltage where $50 \%$ of the complex dissociated $\left(\mathrm{V}_{50 \%}\right)$ was determined for each complex from the dissociation curve. In case of c-Myb DBD complexes with $\mathrm{m} 22$, $\mathrm{m} 19$, and $\mathrm{m} 6$, the crossing point of linear part of the sigmoid curve on $50 \%$ line of the percentage of complex $(\mathrm{R}=50)$ was employed for $\mathrm{V}_{50 \%}$. In other cases, linear part of the sigmoid curve was extrapolated toward lower cone voltage and the crossing point on $50 \%$ line $(R=50)$ was operated for $V_{50 \%}$. Then $-\Delta \Delta G$ of each complex was plotted as a function of $\mathrm{V}_{50 \%}$, as indicated in Figure 8. The SD of $\Delta \Delta G$ determined by filter-binding assay was $0.2 \mathrm{kcal} / \mathrm{mol}$ for every complex [11], and it is indicated with bars in the direction of $y$-axis. Bars in the direction of $x$-axis indicate $S D$ of $V_{50 \%}$ for each complex. Linear regression analysis was carried out for the plot and correlation factor (R) was determined. Positive correlation $(R=0.859)$ was found between $-\Delta \Delta G$ and $V_{50 \%}$. Subsequently, this plot was applied to obtain $\Delta \Delta G$ for two different complexes. Similar experiments were carried out on the complexes of the c-Myb DBD with two other mutant dsDNA, m16 


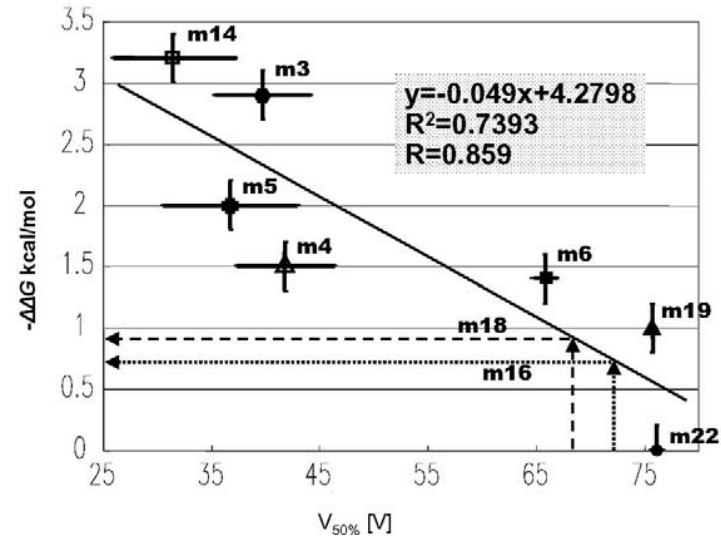

Figure 8. A plot of the solution $-\Delta \Delta G$ of complex as a function of $\mathrm{V}_{50 \%}$ for seven c-Myb DBD-dsDNA complexes. The solution $\Delta \Delta G$ of each complex had been determined by filter-binding assay [11]. The SD of each $\mathrm{V}_{50 \%}$ is indicated with bars on $\mathrm{x}$-axis while that of each $\Delta \Delta G$ value $(0.2 \mathrm{kcal} / \mathrm{mol})$ [11] is indicated with bars on y-axis. The $-\Delta \Delta G$ values for the complexes of c-Myb DBD-m16 (dotted line) and c-Myb DBD-m18 (broken line) were estimated from the obtained $\mathrm{V}_{50 \%}$ by the ESI-CID mass spectra.

(5' CACCCTAACTGGCACACATTCT 3' and its complementary strand) and m18 (5' CACCCTAACTGAAACACATTCT $3^{\prime}$ and its complementary strand). These complexes gave 72 and $69 \mathrm{~V}$ for their $\mathrm{V}_{50 \%}$ (a single experiment for each complex, data not shown), respectively, suggesting its $\Delta \Delta G$ to be -0.7 and -0.9 $\mathrm{kcal} / \mathrm{mol}$ from the plot in Figure 8. These values were very close to the $\Delta \Delta G$ value, $-0.6 \mathrm{kcal} / \mathrm{mol}$, for both complexes determined by the previous filter-binding assay [11].

From the results mentioned above, the present method seems to be able to provide relationship between solution-phase $\Delta \Delta G$ and $V_{50 \%}$. However, for more rigorous quantification of the binding affinity of a protein and dsDNA, improvements should be achieved.

It might be better to examine salt concentration of the buffer according to the degree of binding affinity. For complexes with high binding affinity, such as complexes with $\mathrm{m} 22, \mathrm{~m} 19$, and $\mathrm{m} 6$, complete sigmoid dissociation curves could be plotted and the $V_{50 \%}$ value can be elucidated from the plot directly. In contrast, for the other four complexes with low binding affinity $\left(K \mathrm{~d}>3 \times 10^{-8} \mathrm{M}\right)$, the percentage of complex was less than $40 \%$ even at $50 \mathrm{~V}$ of the cone voltage. Therefore, $\mathrm{V}_{50 \%}$ had to be estimated by extrapolating the linear part of the regression curve toward the lower cone voltage. This should have caused an increase in experimental error, resulting in large SD. If lower concentration of ammonium acetate is used for them, the percentage of complex might be improved at $50 \mathrm{~V}$ of cone voltage. In order to analyze the binding affinity of protein-dsDNA complexes more quantitatively by ESIMS, it might be good to use appropriate concentration of ammonium acetate for each group of complexes with the same order of magnitude of $K \mathrm{~d}$, and to carry out extensive study after rough examination as shown in the present study. In such cases, too, it would be preferable to compensate the contribution from free and bound components present in solution before analysis and from the dissociation product.

The difference in buffer component and temperature between filter-binding assays and ESIMS analysis should be pointed out for more quantitative experiments. In filter-binding assay of the c-Myb DBD and 22mer dsDNA, the protein and DNA was incubated in buffer (100 mM potassium phosphate ( $\mathrm{pH} 7.5), 20 \mathrm{mM}$ $\mathrm{KCl}, 0.1 \mathrm{mM}$ EDTA, $500 \mathrm{mg} / \mathrm{mL}$ of BSA, $5 \%$ glycerol (vol/vol), $10 \mathrm{mM}$ dithiothreitol) on ice and then filtered through nitrocellulose under suction [11]. For ESI measurement, however, nonvolatile buffer cannot be used as the sample solvent; thus, we have to carry out buffer exchange to volatile buffer, such as ammonium acetate, prior to MS analysis. In addition, mass spectra were obtained at room temperature and temperature of the ion source and drying gas was kept 80 and $120^{\circ} \mathrm{C}$, respectively. For more accurate analysis of the solutionand gas-phase dissociation of the complex, compensation on ionic strength, buffer composition, and solution temperature is preferable to be carried out.

Another improvement might be accomplished by the newly-developed soft dissociation method, which enables complete dissociation of the complex without fragmentation of DNA moiety. In the present study, significant degradation of DNA was recognized when increasing the cone voltage. This indicates that collision energy was consumed not only for dissociation of the protein-DNA complex but also for degradation of weak covalent bonds in DNA. For rigorous quantification of the binding affinity of the protein-DNA complex, such degradation should be avoided during the dissociation process. Other activation methods, prompt heating of the inlet of the sample solution, for example, might be effective for more quantitative analysis of the dissociation [21]. We are now trying to apply laser spray, developed by Hiraoka et al. [22, 23], for quantification of binding affinity of c-Myb DBD-dsDNA complexes [24]. This technique might be promising for the quantification of binding affinity of complexes stabilized mainly by hydrogen bonds and/or electrostatic interactions.

\section{Conclusions}

Systematic investigation on gas-phase stability of seven complexes of the c-Myb DBD with 22-mer dsDNA with different solution- $K \mathrm{~d}$ values in wide range $\left(6.3 \times 10^{-7}\right.$ $\mathrm{M}$ to $2.8 \times 10^{-9} \mathrm{M}$ ) was carried out by CID in the first vacuum region of the multiply protonated molecules generated by ESIMS. Protonated molecules of the complex that was prepared in $10 \mathrm{mM}$ ammonium acetate were quite stable in the gas-phase and not easily dissociated even if high cone voltage was applied in the first vacuum chamber source. When the sample was prepared in $500 \mathrm{mM}$ ammonium acetate, however, the 
complexes of c-Myb DBD with its specific dsDNA could successfully be dissociated when increasing the cone voltage, giving multiply protonated molecules of free $\mathrm{c}-\mathrm{Myb} \mathrm{DBD}$ and some DNA fragments. Dissociation curve as a function of cone voltage was plotted, and the cone voltage where $50 \%$ of the complex was dissociated $\left(\mathrm{V}_{50 \%}\right)$ was calculated for each protein-DNA complex. Positive correlation was recognized between the stability of gas-phase molecular ion of the protein-DNA complex and $-\Delta \Delta G$ of the complex in solution. It was also found, however, that several problems still exist that should be resolved for more quantitative investigation of the binding affinity by ESI-MS.

\section{Acknowledgments}

This work was partly supported by Yokohama City Collaboration of Regional Entities for the Advancement of Technological Excellence (Y-CREATE) (to YN) and Special Coordination Funds for the Promotion of Science and Technology (to SA).

\section{References}

1. Fenn, J. B.; Mann, M.; Meng, C. K.; Wong, S. F.; Whitehouse, C. M. Electrospray ionization for mass spectrometry of large biomolecules. Science 1989, 246, 64-71.

2. Ganem, B.; Li, Y.-T.; Henion, J. D. Detection of noncovalent receptor-ligand complexes by mass spectrometry. J. Am. Chem. Soc. 1991, 113, 6294-6296.

3. Katta, V.; Chait, B. T. Observation of the heme-globin complex in native myoglobin by electrospray-ionization mass spectrometry. J. Am. Chem. Soc. 1991, 113, 8534-8535.

4. Light-Wahl, K. J.; Schwartz, B. L.; Smith, R. D. Observation of the noncovalent quaternary associations of proteins by electrospray ionization mass Spectrometry. J. Am. Chem. Soc. 1994, 116, 5271-5278.

5. Loo, J. A. Studying noncovalent protein complexes by electrospray ionization mass spectrometry. Mass Spectrom. Rev. 1997, 16, 1-23.

6. Daniel, J. M.; Friess, S. D.; Rajagopalan, S.; Wendt, S.; Zenobi, R. Quantitative determination of noncovalent binding interactions using soft ionization mass spectrometry. Int. J. Mass Spectrom. 2002, 216, 1-27.

7. Rostom, A. A.; Tame, J. R.; Ladbury, J. E.; Robinson, C. V. Specificity and interactions of the protein OppA: Partitioning solvent binding effects using mass spectrometry. J. Mol. Biol. 2000, 296, 269-279.

8. Lüscher, B.; Eisenman, R. N. New light on Myc and Myb. Part II. Myb. Genes Dev. 1990, 4, 2235-2241.

9. Biedenkapp, H.; Borgmeyer, U.; Sippel, A. E.; Klempnauer, K. H. Viral Myb oncogene encodes a sequence-specific DNAbinding activity. Nature 1988, 335, 835-837.

10. Tanikawa, J.; Yasukawa, T.; Enari, M.; Ogata, K.; Nishimura, Y.; Ishii, S.; Sarai, A. Recognition of specific DNA sequences by the $\mathrm{c}-\mathrm{Myb}$ protooncogene product: role of three repeat units in the DNA-binding domain. Proc. Natl. Acad. Sci. U.S.A. 1993, 90, 9320-9324.

11. Ogata, K.; Kanei-Ishii, C.; Sasaki, M.; Hatanaka, H.; Nagadoi, A.; Enari, M.; Nakamura, H.; Nishimura, Y.; Ishii, S.; Sarai, A. The cavity in the hydrophobic core of Myb DNA-binding domain is reserved for DNA recognition and trans-activation. Nat. Struct. Biol. 1996, 3, 178-187.

12. Sakura, H.; Kanei-Ishii, C.; Nagase, T.; Nakagoshi, H.; Gonda, T. J.; Ishii, S. Delineation of three functional domains of the transcriptional activator encoded by the c-Myb protooncogene. Proc. Natl. Acad. Sci. U.S.A. 1989, 86, 5758-5762.

13. Hofstadler, S. A.; Griffey, R. H. Analysis of noncovalent complexes of DNA and RNA by mass spectrometry. Chem. Rev. 2001, 101, 377-390.

14. Kapur, A.; Beck, J. L.; Brown, S. E.; Dixon, N. E.; Sheil, M. M. Use of electrospray ionization mass spectrometry to study binding interactions between a replication terminator protein and DNA. Protein Sci. 2002, 11, 147-157.

15. Cheng, X.; Harms, A. C.; Goudreau, P. N.; Terwilliger, T. C.; Smith, R. D. Direct measurement of oligonucleotide binding stoichiometry of gene $\mathrm{V}$ protein by mass spectrometry. Proc. Natl. Acad. Sci. U.S.A. 1996, 93, 7022-7027.

16. Potier, N.; Donald, L. J.; Chernushevich, I.; Ayed, A.; Ens, W.; Arrowsmith, C. H.; Standing, K. G.; Duckworth, H. W. Study of a noncovalent trp repressor: DNA operator complex by electrospray ionization time-of-flight mass spectrometry. Protein Sci. 1998, 7, 1388-1395.

17. Craig, T. A.; Benson, L. M.; Tomlinson, A. J.; Veenstra, T. D.; Naylor, S.; Kumar, R. Analysis of transcription complexes and effects of ligands by microelectrospray ionization mass spectrometry. Nat. Biotechnol. 1999, 17, 1214-1218.

18. Hanson, C. L.; Robinson, C. V. Protein-nucleic acid interactions and the expanding role of mass spectrometry. J. Biol. Chem. 2004, 279, 24907-24910.

19. Ogata, K.; Morikawa, S.; Nakamura, H.; Sekikawa, A.; Inoue, T.; Kanai, H.; Sarai, A.; Ishii, S.; Nishimura, Y. Solution structure of a specific DNA complex of the Myb DNA-binding domain with cooperative recognition helices. Cell 1994, 79, 639-648.

20. Ogata, K.; Morikawa, S.; Nakamura, H.; Hojo, H.; Yoshimura, S.; Zhang, R.; Aimoto, S.; Ametani, Y.; Hirata, Z.; Sarai, A.; Ishii, S.; Nishimura, Y. Comparison of the free and DNAcomplexed forms of the DNA-binding domain from c-Myb. Nat. Struct. Biol. 1995, 2, 309-320.

21. Daneshfar, R.; Kitova, E. N.; Klassen, J. S. Determination of protein-ligand association thermochemistry using variabletemperature nanoelectrospray mass spectrometry. J. Am. Chem. Soc. 2004, 126, 4786-4787.

22. Hiraoka, K. Laser sprayElectric field-assisted matrix-assisted laser desorption/ionization. J. Mass Spectrom. 2004, 39, 341350.

23. Kudaka, I.; Kojima, T.; Saito, S.; Hiraoka, K. A comparative study of laser spray and electrospray. Rapid Commun. Mass Spectrom. 2000, 14, 1558-1562.

24. Takamizawa, A., Itoh, Y., Osawa, R., Iwasaki, N., Nishimura, Y., Akashi, S., Hiraoka, K Selective dissociation of noncovalent bonds in the biological molecules by laser spray. J. Mass Spectrom., 2004, 39, 1053-1058. 